\title{
ESTADO E AMIZADE
}

\author{
STATE AND FRIENDSHIP
}

\author{
KONRAD UTZ \\ (UFC / Fortaleza)
}

\begin{abstract}
RESUMO
O presente artigo pretende apresentar um novo ponto de partida para explicar e justificar o poder político: a amizade. Como tal, ele tem um carater programático. Em virtude dessa finalidade, ele analisa, de forma muito resumida e, necessariamente, generalizante, o discurso filosófico atual sobre o poder político e idenficia o comunitarismo e o contratualismo como suas vertentes mais fortes, quase exclusivas. Ambas são criticadas pelo princípio unilateral da identidade implicitamente pressuposto por elas. A Filosofia Política da Amizade é proposta como alternativa a essas, já que seu princípio fundamental é capaz de dar conta não apenas da união e da indentidade, mas também da diferença e da alteridade irredutível. Este princípio é introduzido e desdobrado a partir da Teoria da Amizade de Aristóteles. Em seguida, algumas consequências de tal filosofia política para os debates atuais são resumidamente esboçadas.
\end{abstract}

Palavras-chave: Filosofia política. Amizade. Poder. Estado.

\begin{abstract}
The articles aim is to present the concept of friendship as a basis for the explication and justification of political power. Thus being programmatic in character, it analyzes in current philosophical debate on political, broadly generalizing, two mainstreams: communitarianism and contractualism. Both are criticized for assuming the onesided principle of identity as their basis. Political Philosophy of Friendship is proposed as an alternative, as its fundamental principle is capable of accounting not only for unity and identity, but also for difference and alterity. This principle is introduced and developed parting from Aristotle's Theory of Friendship. The last part sketches out some consequences for current debates.
\end{abstract}

Keywords: Political Philosophy. Friendship. Power. State.

\section{Comunitarismo e Contratualismo}

$\mathrm{Na}$ discussão da Filosofia Política atual, podemos distinguir duas formas principais de fundamentação do estado. Inicialmente, existem aquelas teorias que consideram a comunidade como algo originário, irredutível e imprescindível, que são as teorias que podemos chamar comunitaristas. O indivíduo ou é secundário à comunidade política ou pelo menos dependente dela em aspectos essenciais de sua existência; i.e., o ser humano individual não poderia ser o que ethic@-Florianópolis, v. 11, n. 1, p.87-103 Jun. 2012. 
ele é sem ela, e, consequentemente, se essa comunidade for organizada na forma de um estado: sem o estado. Em segundo lugar, existem as teorias que consideram, ao contrário disso, o estado como algo secundário, derivado. O estado só é constituído a partir dos indivíduos, pelos indivíduos; ele é derivado da vontade deles. A formação do estado tem, portanto, o caráter de um acordo ou de um convênio dos indivíduos autônomos propulsionados pelos seus interesses subjetivos. ${ }^{1}$ Um tal convênio chama-se "contrato". A segunda forma da fundamentação do estado é, portanto, o Contratualismo.

Ambos, o comunitarismo e o contratualismo, podem ser divididos em três subcategorias. O comunitarismo apresenta-se, inicialmente, numa forma que podemos chamar de “comunitarismo natural”. Neste, quem obriga os indivíduos a conviverem num estado e quem, até certo ponto, os subjaz à comunidade, é um princípio natural. Este princípio natural pode ser a ordem do cosmo, a lei natural ou a vontade do Deus criador da natureza. Em Aristóteles, e até certo ponto também em Platão, este princípio natural é o princípio específico da natureza humana, i.e., a sua essência. O homem é, segundo Aristóteles, um zoon politikón, um "animal político". A convivência política, num estado, é seu telos, seu fim imanente. Se o homem não vive numa comunidade política, ele não pode cumprir a finalidade de sua própria existência e, portanto, não pode ser plenamente virtuoso, nem realmente feliz.

A segunda forma do comunitarismo, o comunitarismo histórico, é a forma mais atual do comunitarismo. De fato, o nome "comunitarismo" foi formulado e reivindicado por essa corrente de tal forma que normalmente "comunitarismo" é entendido simplesmente como "comunitarismo histórico". Com essa terminologia, a diferença dos comunitarismos é, às vezes, ofuscada, pois os comunitaristas históricos costumam chamar pensadores como Aristóteles e Hegel de “comunitaristas" sem ver ou dizer claramente que os princípios dos comunitarismos destes não eram históricos. O comunitarismo histórico baseia seu princípio na epistemologia e na antropologia. Ele nega que existam, pelo menos no campo da ética e da política, princípios universais e imutáveis, sejam estes princípios naturais ou ideais. Ao mesmo tempo, ele mantém que nosso conhecimento pressupõe um quadro referencial de linguagem, conceitos, práticas e, principalmente, valores. Este quadro referencial é, consequentemente, por um lado, histórico e contingente, e não universal e não absoluto. Por outro lado, ele é insuperável para o indivíduo, porque predetermina nossas possibilidades de compreensão, de pensar e, mais importante, de avaliação. $\mathrm{O}$ aspecto antropológico desta posição é que o homem é o que ele é apenas dentro de 
um tal quadro referencial histórico comunal. Nós somos definidos pelas comunidades históricas nas quais vivemos; nós nos definimos a nós mesmos dentro dos padrões destas. Talvez o primeiro comunitarista histórico neste sentido tenha sido Marx. Ele defendia, além da interpretação materialista do quadro referencial histórico-comunal, apenas uma tese adicional que distingue-o fundamentalmente dos comunitaristas atuais. Marx pensava que havia uma lei da história, uma necessidade imanente do desenvolvimento dela. Mesmo quem entendesse essa necessidade não poderia bem "sair" de sua época; contudo, poderia visar a época seguinte e, a partir disso, desenvolver uma prática para realizá-la. Essa época posterior à atual do capitalismo seria a época do socialismo e, finalmente, do comunismo. A prática para realizá-la seria a revolução.

A última forma do comunitarismo é a idealista. Nessa, o princípio que determina tanto a primazia da comunidade política quanto sua forma específica é um princípio ideal, um princípio da razão. Até certo ponto Platão já foi um comunitarista idealista, porque achava que a própria razão determinava os seres humanos a conviverem politicamente e a subordinar-se comunalmente a essa razão - apresentada, na República, pelos Filósofos-Reis, e, nas obras posteriores, mais pelas leis. Mas o grande protagonista dessa forma do comunitarismo foi Hegel. Ele achava que o Espírito, em seu auto-desenvolvimento imanente, transcende sua auto-compreensão de espírito individual e chega a uma auto-compreensão comunal como espírito de um povo e, ultimamente, de um estado. Esta, segundo Hegel, é a forma final e perfeita do Espírito em sua realização em espaço e tempo. Para além dela, ainda há o Espírito Absoluto, mas o estado é o Absoluto na terra.

Todas as três formas de comunitarismo têm suas respectivas problemáticas. O problema do comunitarismo natural é a pressuposição do princípio natural, p.ex., na forma de uma essência humana. Essa noção parecia evidente para Platão e Aristóteles, mas hoje em dia poucos aceitamna. Portanto, seria necessário fornecer argumentos a favor de um tal princípio de "natureza humana" ou "essência humana". Tais argumentos, até hoje, não foram apresentados de uma forma convincente. A opção do comunitarismo histórico pode apresentar-se até como consequência deste fracasso. Se não existe um princípio invariável, geral, os princípios da comunidade, consequentemente, precisam ser históricos, contingentes. Isso pode até ser convincente quanto aos princípios específicos dentro das comunidades, por exemplo, quanto ao sistema de seus valores. Mas o comunitarismo histórico não defende apenas estes princípios. Ele defende que estes são os únicos princípios axiológicos que existem e que o espírito do indivíduo é incapaz de superá-los ou que a capacidade para fazer isso seja muito limitada. Agora, este 
princípio da contingência dos princípios e da determinação do indivíduo pelo quadro referencial comunal histórico no qual ele nasceu e cresceu é o meta-princípio do comunitarismo, o princípio que define o comunitarismo e o caráter comunitário dos princípios axiológicos como tais. Este princípio é necessariamente universal e apriórico. Ele não pode ser, por sua vez, um princípio comunal-histórico contingente. Portanto este princípio invalida-se a si mesmo: ele nega sua própria possibilidade. $^{2}$ Em comparação a essas duas opções, o comunitarismo idealista parece a forma melhor argumentada. O ponto de partida de sua argumentação é a própria subjetividade pensante. Essa nós mal podemos negar, pois o próprio discurso argumentativo já pressupõe essa subjetividade. Porém, o comunitarismo idealista é muito otimista quanto às possibilidades do auto-esclarecimento dessa subjetividade pensante. Além disso, ele parece desrespeitar outros aspectos da subjetividade, as emoções, por exemplo, que não permitem de uma universalização e que, portanto, apresentariam um obstáculo à superação do espírito individual rumo ao espírito comunitário como verdadeira identidade dos indivíduos. Parece que aquela subjetividade que o comunitarismo idealista assume como fundamento é uma subjetividade reduzida, abstrata, unilateral.

Além destes problemas nas pressuposições do comunitarismo, existe um problema grave quanto a suas consequências. No comunitarismo, o todo da comunidade é, de um forma ou outra, um valor em si mesmo, independentemente dos valores e finalidades subjetivas dos indivíduos. Além disso, a relação entre os valores comunitários e subjetivos-individuais sempre é, até certo grau, assimétrica. O sistema de valores comunitário tem a primazia. Essa primazia, dependendo da forma específica de comunitarismo, não precisa ser absoluta. Mesmo assim, o comunitarismo sempre tem uma certa tendência ao totalitarismo da comunidade e da cultura e, consequentemente, se a forma institucional for o estado, ao totalitarismo do estado. A maioria dos comunitaristas tenciona mitigar essa tendência, mas é difícil defender a liberdade irrevogável do indivíduo se este próprio indivíduo se constitui apenas no seio da comunidade e em virtude dos valores desta. Como o indivíduo pode ser independente se sua própria existência depende do todo social? A expressão figurativa dessa supremacia do todo da comunidade e, mais especificamente, do estado, é o conceito do organismo ou do sujeito comunal. O estado, conforme essa visão, é concebido como um grande organismo ou como um sujeito só, um indivíduo, por sua vez. Em ambos os casos, a finalidade última evidentemente é aquela do todo, e os orgãos no organismo ou, respectivamente, os espíritos particulares no espírito do todo precisam subordinar-se a essa 
finalidade. Se os orgãos não colaboram mais para o bom funcionamento do todo, o organismo está doente e pode até morrer. Foi Popper ${ }^{3}$ que chamou atenção ao grande perigo implícito a essas imagens tão populares do estado, deste Platão.

O Contratualismo, ao contrário disso, não vê no estado algo que, de alguma forma, supere os indivíduos ou apresente uma condição constitutiva deles. Na visão contratualista, o estado é uma função dos indivíduos, e não o contrário. Como essa função é legitimadora, e não histórica, a grande maioria dos contratualistas não quer defender que os estados - ou algum primeiro estado original - foram, de fato, formados pelo fechamento de um contrato por um grupo de indivíduos reais. Normalmente, os contratualistas desvinculam a gênese histórica do estado da construção sistemática de sua legitimação. Só que eles concebem essa última, apesar dessa desvinculação, na forma de uma "história", de um acontecimento em espaço e tempo. Os contratualistas, por sua maioria, propõem uma reconstrução hipotética, fictícia do poder político. Essa história fictícia, independentemente das várias formas do contratualismo, tem o seguinte conteúdo: indivíduos livres, que são fundamentalmente iguais e egoístas encontram-se numa situação inicial bem definida. Essa situação tem um defeito inaceitável - normalmente esse defeito é a conflituosidade da convivência na situação original, seja essa a guerra de todos contra todos ou seja apenas a insegurança jurídica. Para sair dessa situação, os indivíduos optam por um consenso estratégico racional. Essa racionalidade é apenas instrumental, i.e., ela apenas ajuda ao indivíduo a realizar melhor suas finalidades já definidas por ele, ela não prescreve finalidades e valores racionais universais ao indivíduo, como no caso do comunitarismo idealista. Este consenso define a limitação mútua e definitiva da liberdade individual pelos próprios indivíduos, i.e., em virtude de sua liberdade. Um tal convênio chama-se contrato.

Há vários pontos problemáticos nessa teoria. O primeiro é que o contratualismo, na grande maioria de suas formas, disvincula a gênese histórica e, com isso, a realidade histórica do estado de sua fundamentação legitimadora. Desta forma, o contratualismo sempre tem um aspecto anistórico, abstrato. Esta caraterística o contratualismo compartilha com o comunitarismo naturalista e idealista, pois, para ambos, o estado é uma realidade originária e "anterior" aos indivíduos e às demais comunidades, mesmo que seja, evidentemente, historicamente posterior aos indivíduos e às comunidades, como a família ou a tribo. Apenas o contratualismo histórico é "realista" neste sentido. As várias formas do contratualismo distinguem-se quanto ao alcance da legitimação, quanto ao grau da limitação da liberdade individual e da transferência de seus 
direitos, quanto à forma específica do contrato e os bens individuais garantidos pelo contrato. A diferença fundamental, porém, está na interpretação da situação inicial e, com isso, dos pressupostos do contrato. Quanto a isso, a forma mais simples do contratualismo é o contratualismo estratégico que não assume qualquer base do contrato fora dos interesses egoístas dos indivíduos junto com a razão instrumental que calcula as vantagens pessoais e desenvolve a melhor estratégia para realizá-los. Como qualquer contratualismo, o contratualismo estratégico precisa assumir também a liberdade, mas neste caso essa é apenas negativa, i.e., ela define-se apenas pela ausência de regras, leis e autoridades que possam restringir as vontades individuais. Tais normas e autoridades apenas o contrato vai estabelecer.

Ao contrário disso, o contratualismo jusnaturalista e o contratualismo moral assumem que já exista, na situação inicial, uma realidade normativa. O contrato será estabelecido, portanto, à base dessa. Ele não é mais a fonte originária de qualquer obrigação. Em Locke e naqueles liberalistas que seguem-no, essa realidade normativa é a lei natural que garante aos indivíduos o direito à vida, à liberdade e à propriedade. Em Kant, as estruturas normativas pressupostas no contrato já são bem mais complexas e mais completas: toda a moral, para Kant, é constituída pela razão individual e existe, portanto, já na situação inicial. Já são indivíduos morais que fecham o contrato. Porém, as diferenças entre os três tipos básicos do contratualismo, além das inúmeras formas específicas, não têm tanta importância para nossa argumentação como a diferenciação das várias formas do comunitarismo.

O comunitarismo define a comunidade política como um Bem-em-si, como o Bem original ou, em alguns casos até como o "Meta-Bem", isso é, como aquela realidade que é condição da possibilidade do Bem ou da noção do Bem. Portanto, tudo depende da fundamentação argumentativa deste Bem. Esta é diferente nos três tipos de comunitarismo, mesmo que, como tentei argumentar, nenhuma dessas argumentações seja realmente satisfatória.

Diferente disso, as deficiências básicas dos vários contratualismos são comuns a todos eles. Estas deficiências foram bem formuladas pelos comunitaristas de nossos dias, i.e., os comunitaristas históricos, mas já encontram-se em Hegel e outros. As principais críticas são duas: o indivíduo na situação inicial fictícia é mesmo uma ficção: um indivíduo totalmente abstrato, sem laços sociais, sem noções de valores. O problema não é que os contratualistas abstraem de algumas caraterísticas que todo indivíduo real tem. Eles abstraem de caraterísticas constitutivas dos indivíduos. Isto é, se pensarmos num indivíduo sem laços sociais e sem noções de valores, 
não estamos pensando mais num indivíduo humano. O homem é o que ele é apenas nestes laços sociais, ele define-se apenas à base de valores já dados a ele. Sem esta base, ele seria um indivíduo apessoal, um indivíduo-ninguém. Este argumento talvez não apanha os contratualistas jusnaturalistas e morais, mas se estes assumem relações sociais e valores predefinidos, eles já admitem que os mesmos não são constituídos pelo contrato. Portanto, já pressupõem uma base não-contratualista do contrato. ${ }^{4} \mathrm{O}$ segundo problema do contratualismo é que a função da legitimação consiste nas caraterísticas de um processo. O poder político é justificado se ele puder ser reconstruído (ou de fato for estabelecido) como resultado do processo do fechamento de um contrato entre indivíduos livres, egoístas. Este, evidentemente, é um critério meramente formal, como qualquer critério procedimental. O resultado é legitimado pela forma do procedimento de sua formação, não por seu conteúdo. O conteúdo de teorias e visões normativas normalmente é compreendido sob o conceito do Bem. Portanto, pode-se formular que ao contratualismo enquanto tal falta uma noção do Bem ou de Valores. Mas sem uma tal noção do Bem, os comunitaristas argumentam, o indivíduo nem poderia exercer seu raciocínio estratégico na situação inicial. Sem ter valores ele não teria uma base para este cálculo. As inclinações naturais imediatas não bastam, pois estas precisariam ser avaliadas para poderem ser comparadas. Para isso, é necessário um parâmetro geral, objetivo que as sensações imediatas de prazer e dor enquanto tais não fornecem. Diante desta crítica, alguns contratualistas, como John Rawls, por exemplo, concedem que eles assumem certos valores e que, de fato, aceitam estes valores como base do cálculo estratégico do contrato. Pode ser que, com isso, eles salvem suas teorias da crítica. Mas é evidente que, desta forma, eles deixam de ser contratualistas puros. A grande questão é, portanto, de onde é que eles tomam seus valores básicos. Neste momento, voltamos ao problema fundamental do comunitarismo: o problema da fundamentação argumentativa do Bem comunitário.

\section{Filosofia política da Amizade}

Considerando as vantagens e os problemas do comunitarismo por um lado e do contratualismo pelo outro, seria desejável, como muitas vezes, um modelo de filosofia política que consiga reconciliar os dois, evitando as falhas de cada um e guardando o que ambos têm de bom. De fato, a discussão entre comunitaristas e liberalistas contratualistas moveu-se na direção 
de uma tal síntese. Eu também quero propor, na forma da "Filosofia da Amizade", um tal modelo. Mas antes de fazer isso quero apontar um erro que, a meu ver, é comum tanto ao comunitarismo quanto ao contratualismo. Ambos partem da unidade e da identidade. Os comunitaristas partem da unidade da comunidade e de sua identidade, constituída pelo etos comum, i.e., pelos valores morais e culturais, as estruturas sociais e as regras de convivência, inclusive suas leis no sentido estrito. Os contratualistas partem da unidade imprescindível do sujeito individual enquanto identidade última, não superável, não redutível e não dissolúvel numa identidade superior. ${ }^{5}$ Quando o comunitarismo, na forma do organicismo comunitário, é levado a seu extremo, até podemos formular que ele, tanto como o contratualismo, parte do conceito de um indivíduo absoluto. $\mathrm{O}$ indivíduo absoluto do contratualismo é o indivíduo particular. $\mathrm{O}$ indivíduo absoluto do comunitarismo extremo é a comunidade enquanto um único sujeito em si, como "um só homem". Existe um isomorfismo estrutural entre contratualismo e comunitarismo, uma concordância fundamental no fundo de suas diferenças: a opção pela unidade, pela identidade e até pela individualidade. Foi Platão que, pela primeira vez, expôs essa isomorfia entre indivíduo particular e indivíduo estatal. Na República ele explica a alma a partir das estruturas do estado ideal - e até certo ponto, vice- versa. O estado é, então uma alma alargada; e a alma é um estado minúsculo.

É interessante que Aristóteles, exatamente no mesmo lugar sistemático da explicação das estruturas e das formas do estado, oferece uma alternativa. Platão explica tanto o funcionamento geral quanto as formas específicas do estado, que são a monarquia, a aristocracia e a democracia, relacionando as três classes do estado ideal dele às três partes da alma. ${ }^{6} \mathrm{~A}$ monarquia corresponde ao domínio da parte raciocinante da alma, o estado aristocrata ao domínio da parte irascível dela e a democracia, que Platão despreza, ao domínio da parte concupiscente da alma. Aristóteles assume o mesmo modelo das três formas básicas de estado. E, assim como Platão, ele pretende explicar como cada uma delas funciona, quais são seus méritos e suas desvantagens e de que maneira uma pode transformar-se na outra, como acontece muitas vezes na história. Mas o modelo explicativo para Aristóteles não é a alma e suas partes. A explicação dele não parte do indivíduo, ela parte de uma estrutura não intra-subjetiva, mas intersubjetiva. $\mathrm{O}$ modelo explicativo do estado em Aristóteles é a amizade. ${ }^{7}$

Com isso já cheguei à alternativa que queria propor ao individualismo, tanto contratualista quanto comunitarista, na filosofia política atual. Partindo da teoria da amizade de Aristóteles 
quero defender que a solução está nem no contratualismo nem no comunitarismo nem em alguma mescla ou num compromisso entre os dois. A solução está na mudança radical do conceito fundamental sob o qual essas teorias são concebidas. Nenhuma teoria será satisfatória se ela for concebida unilateralmente sob o conceito da identidade.

Evidentemente a solução não será optar pelo oposto, pela não-identidade, pela nãounidade, pela diferença, pela mulitiplicidade e relatividade. Até certo ponto o Pós-Modernismo pode ser visto como tentativa de desenvolver tal conceito teórico oposto ou complementar às filosofias da identidade. Não posso, aqui, entrar na argumentação contra tais "fillosofias da diferença" ou até da "diferânce". Elas são ainda mais problemáticas que as filosofias da identidade. Por enquanto, só posso apontar que a opção pela não-identidade é igualmente unilateral como aquela pela identidade.

No caso de duas opções unilaterais, cada uma insuficiente por si, o natural é buscar uma síntese delas ou uma "via média", como Aristóteles avoca em sua doutrina da virtude. Mas em nosso caso isso parece inviável. Porque o idêntico e o não-idêntico, a unidade e a diferença são alternativas exclusivas, não existe uma terceira, não existe nada "no meio" desses. Não podemos, por via teórica, construir uma síntese das duas opções unilaterais. Essa síntese seria ou contraditória, porque reúne dois mutualmente excludentes; ou ela seria uma síntese unilateral por sua vez: uma identidade de identidade e não identidade ou uma não-identidade de identidade e não-identidade. Preciso anotar aqui que Hegel pensou ter achado uma solução para o problema. Acho que ele estava errado, não existe solução. Mas não tenho o tempo para explicar isso aqui. ${ }^{8}$

Nós não somos capazes de pensar a síntese que queríamos e, mesmo assim, nós precisamos dessa síntese. Essa exigência não é apenas um desiderato prático, ela é uma necessidade lógica. Outra vez, não tenho, aqui, o espaço para explicar isso e para indicar quais sejam as consequências teóricas disso. Mas no caso de nosso problema, existe uma outra saída. Em vez de buscar por soluções no armazém das opções teóricas, podemos buscar a saída na própria realidade. Qual é aquela realidade na qual identidade e alteridade existem juntos, onde indivíduos formam uma união sem perder sua diferença, onde existem estruturas normativas e valores comuns sem que os indivíduos se tornem meras funções deles? Quando perguntamos assim, chegamos logo àquele ponto de partida que já propus antes: à amizade.

$\mathrm{Na}$ amizade duas ou mais pessoas se reúnem porque eles desejam um ao outro. Este é o primeiro sentido do amar: o amor é, em primeiro lugar, um interesse egocêntrico que tenho pelo 
outro. Ele é um bem para mim. Aristóteles distingue três bens que os amigos podem desejar um do outro: eles podem esperar ou algum proveito dele, ou um prazer ou eles podem desejar a presença do amigo porque ele é bom em si mesmo e eles se alegram simplesmente por sua excelência ou seu caráter "virtuoso". Não vou entrar aqui da distinção dos vários tipos de amizade que Aristóteles expõe a partir disso. Apenas quero apontar ao fato que os motivos da amizade, nem em Aristóteles nem por nosso entendimento comum, precisam ser altamente éticos e virtuosos. A amizade começa com o interesse próprio. Este interesse pode ser nobre, como no caso do desejo pelo bom caráter do outro, ou menos nobre, como no caso do desejo por alguma utilidade. Para a amizade enquanto tal isso não importa. $\mathrm{Na}$ amizade, quero o outro para mim, porque ele é, em meus olhos, um bem para mim. E se meu amor não é unilateral, se o outro é meu amigo também, ele quer ser este bem para mim. O amigo está feliz sabendo que ele é bom para seu amigo. E ele vai alegrar-se em dar este bem a este. Se admiro o caráter do outro, ou se desejo, no amor erótico por exemplo, meu prazer de quem amo, ou se peço a ajuda de meu amigo - i.e., se eu, de tais maneiras, manifesto meu interesse egoísta na amizade, o outro não estará ofendido, chocado. Bem pelo contrário, este ser-desejado será seu prazer. Se, ao contrário disso, trato meu amigo de maneira totalmente desinteressada, como na caridade cristã, só querendo o bem maior para ele, não desejando nada dele; se nem me importo se ele é gentil ou não, virtuoso ou não, bonito ou não, prazeroso ou não; se nem me importa o que fala e faz - se manifesto uma tal ausência de interesse egocêntrico por meu amigo, ele não estará contente com tanto altruísmo desinteressado. Bem pelo contrário ele estará chateado, talvez profundamente magoado. "Meu amigo nem se interessa por mim", pensará. Na amizade, nós desejamos o desejo do outro, seja este desejo ético, estético ou até utilitário. A primeira caraterística da amizade é, então, o desejo.

A segunda é o conhecer ou a consciência. O desejo na amizade não é um reflexo inconsciente, como, p.ex., às vezes começo de coçar-me em reação a uma senação de cóçegas sem notá-la conscientemente. O amor também não é um simples reflexo, como p.ex. o espirrar em reação a uma irritação na nariz. No amor, tenho consciência do outro, de sua bondade ou atratividade para mim e tenho consciência de meu próprio desejar. É bem verdade que o amor, pelo menos inicialmente, não é um ato livre no sentido kantiano, i.e., ele não é causado pela pura autonomia do sujeito amante. Ele é causado pela inclinação, pelo desejo que a consciência do outro provoca. Mas ao mesmo tempo o amor implica sua própria consciência e, com isso, sua própria reflexão. Por causa disso, cada um que tem consciência de amar encontra nessa 
consciência-amante a consciência de si mesmo - e não apenas enquanto autoconsciência abstrata, de um sujeito transcendental, mas enquanto eu existencial, altamente envolvido no processo. No amor nós temos uma consciência profunda do envolvimento e do compromisso de nossa própria pessoa. Essa autoconsciência comprometida e decidida é, a meu ver, a origem da liberdade, mas nisso não posso entrar aqui.

Além destes dois aspectos egocêntricos da amizade Aristóteles enumera dois complementares que se dirigem ao outro: o respeito e a benevolência pelo outro. ${ }^{9}$ Estes não são apenas aspectos adicionais aos primeiros. No caso do respeito e da benevolência do amor amigável original não se trata de uma benevolência qualquer, geral e indistinta que tenho em relação a meu amigo, nem de um respeito abstrato. A benevolência e o respeito são os outros lados de meu desejo e meu conhecer. O mesmo bem que desejo do outro para mim também desejo para ele. Assim como desejo ele para mim como um bem para mim, quero ser desejado pelo outro, quero ser um bem para ele. E meu respeito refere-se àquilo que meu amigo é, i.e., àquela personalidade na qual reconheço ele. Isso implica que respeito ele em seu caráter específico. E isso, por sua vez, implica que respeito-o não apenas em suas caraterísticas universais, de ser humano, ser racional, ser moral, nas quais ele é igual a mim e a todos os outros, mas que respeito meu amigo naquilo que ele tem de específico, de individual e incomparável. Respeito meu amigo nas diferenças que ele tem quanto a mim e quanto a qualquer outra pessoa. Respeito a sua alteridade.

Estes quatro momentos da amizade, desejo, conhecer, benevolência e reconhecer, Aristóteles resume na fórmula do "heteros autos": o amigo é, para mim, um "outro eu-mesmo". Isso tem dois sentidos: primeiro, o amigo é para mim da mesma maneira como eu mesmo sou para mim. Assim como eu reconheço a mim mesmo na autoconsciência e principalmente na autoconsciência-amante, eu reconheço o outro como um Eu-próprio e não apenas como um objeto. O mesmo vale para o aspecto volitivo: assim como eu quero para mim mesmo, eu quero, no amor, para meu amigo, quero bem a ele. Este aspecto, nós podemos chamar de o aspecto igualitário do "outro eu-mesmo". Mas a fórmula também expressa o aspecto oposto, complementar: entendendo que o amado é um outro eu-mesmo, eu compreendo que ele é, assim como eu, uma realidade incomparável, irredutível a qualquer outra, incomensurável por metros objetivos-gerais, uma realidade fundamentalmente não-idêntica a todas as outras. $\mathrm{O}$ outro eumesmo é alteridade originária. E eu reconheço e quero meu amigo enquanto tal alteridade 
imprescindível. Isso é, concedo a ele a liberdade de não enquadrar-se plenamente em meu sistema de desejos, valores e regras sociais.

Com os quatro elementos do conhecer, do desejar, do reconhecimento e da benevolência com seus dois aspectos fundamentais da identificação e da alteridade, Aristóteles define o amor originário. Se este amor for recíproco, a amizade começa. Pelo próprio desejo que os amigos têm pelo outro eles começam a viverem juntos, agirem juntos e comunicarem constantemente. Com isso sua relação se fortalesse, aprofunda e concretiza. Do amor inicial cresce a amizade real. Este estabelecimento da amizade implica dois pontos fundamentais: um interno e um externo. Qualquer amizade estabelece, ao longo da vivência dela, estruturas. Essas podem ser explícitas, mas por sua maioria são implícitas. As estruturas definem os bens que os amigos trocam, as finalidades que eles realizam juntos, os modos de sua convivência, a identidade dos amigos e seus papéis dentro da amizade, as regras de sua convivência e, sobretudo, os valores que os amigos reconhecem e nos quais eles se reconhecem mutualmente enquanto bons. Em breve, cada amizade estabelece um étos. Este é o aspecto interno. O aspecto externo é a diferenciação entre a comunidade dos amigos e os estrangeiros. Essa diferenciação, no primeiro momento, é inócua. É uma consequência automática: se fecho uma amizade com certas pessoas, todas as outras pessoas serão, em relação a essa, não-amigos. Elas permanecem fora.

Ambos os pontos, tanto o étos comunitário da amizade quanto sua exclusividade, evidentemente, tem um potencial muito problemático. O étos comunitário tem a tendência de crescer cada vez mais, de fixar-se e de petrificar-se, até o ponto que ele domina a própria amizade, até que, finalmente, os membros da comunidade não convivem mais livremente como amigos, propulsionados pelo amor, mas obedecendo ao étos, como súditos da identidade comunal.

A diferenciação entre o interno e o externo da comunidade talvez seja mais problemática ainda. Evidentemente ela tem a tendência de fechar a comunidade e de considerar qualquer estrangeiro, qualquer sujeito que não se enquadra em seu dela e não obedece a este, como inimigo. ${ }^{10}$ Estes dois perigos tornam-se mais problemáticos ainda quando observamos o seguinte: o amor amigável é, para Aristóteles, a origem de qualquer comunidade. Mas, uma vez que esta comunidade for estabelecida, indivíduos - que não escolheram e não formaram o étos dessa comunidade - podem nascer nela ou ser incorporados nela. 
E isso, de fato, é o caso na maioria das comunidades nas quais vivemos. Seja na família, seja no estado, na religião, na empresa onde trabalhamos, nós já encontramos um étos pronto e precisamos subordinar-nos a este. E mais que isso, este étos, não apenas no caso das crianças, forma nossa identidade e nossos valores. Nós definimos nossa existência, até um alto grau, a partir dos étos das comunidades exitentes. Nisso, os comunitaristas históricos estão certos.

Mas, felizmente, essa não é a única realidade que observamos. E aí a filosofia da amizade diferencia-se do comunitarismo histórico. O próprio amor amigável tem o potencial de corrigir os erros e de superar as limitações das estruturas fixadas das comunidades. Em vez de obedecer a essas estruturas e seguir os valores comunais estabelecidos, os membros da comunidade podem fechar novas amizades e podem reoriginar o reconhecimento e a benevolência autêntica pelo outro. Isso pode acontecer dentro da comunidade, como, p.ex. no século 18, quando algumas pessoas deixaram de ver numa menina solteira que ganhava um filho uma criminosa que feriu o étos comum, mas descobriram nela uma pessoa que é vítima deste étos e que precisa da ajuda da sociedade. A mudança do étos pode acontecer com respeito às relações exteriores da comunidade, quando seus membros fecham amizades com membros de uma outra comunidade que até então era uma comunidade inimiga. Isso pode, com o tempo, levar até o ponto que as próprias comunidades tornam-se amigas, como foi o caso com o povo françês e o povo alemão depois da segunda guerra mundial. Por último, o amor amigável pode levar as pessoas a reconhecerem e quererem bem a outros que, até então foram desrespeitados. Assim, por exemplo, mais e mais pessoas nos sec. 18 e 19 sentiram-se impulsionados a plenamente reconhecer os então escravos e a ver nessas pessoas o "outros eu-mesmos" que não podem ser negados os direitos humanos concedidos aos demais membros da comunidade. E no sec. 20, finalmente, as comunidades políticas européias e americanas chegaram a dar os plenos direitos e o reconhecimento igual a seus membros femininos. Estes são alguns exemplos positivos. Existem inúmeros exemplos onde o amor não conseguiu e não consegue corrigir estruturas comunais petrificadas que impedem o reconhecimento e a benevolência mútua de seus membros. E existem tantos casos onde o amor amigável não conseguiu superar as inimizades entre as culturas, os povos, as religiões, as classes e as famílias.

Isso é o caso, porque a amizade não é um princípio teórico no sentido tradicional do termo. Tal princípio determina universalmente e determina com necessidade. O novo princípio da amizade não faz isso. Ele não garante pela solução. Não garante pela reconciliação, pela 
liberdade, pela paz. A amizade é um princípio ambíguo, muito problemático. Ele tem uma tendência a destruir a si mesmo, de estabelecer estruturas e divisões que, em vez de fortalecer e aprofundar a amizade, impossibilitam o reconhecimento e a benevolência. Pelo outro lado a amizade contém o potencial para corrigir essas tendências e ela contêm critérios imanentes para tal correção. Só que isso não acontece automaticamente, nem pela astúcia de uma razão hegeliana universal atrás das ações cegas dos indivíduos. Quem vai realizar a amizade, quem vai realizar o reconhecimento e a benevolência tanto em nossas relações pessoais quanto nas estruturas gerais de nossas sociedades, somos nós. A amizade não é um princípio a obedecer. Ela é um princípio que precisa ser livremente e criativamente inventado e realizado, cada vez de novo.

Portanto, o amor amigavel pode ser chamado um princípio intrinsecamente e insuperavelmente dialético. O amor amigável, o desejo, o conhecimento, a benevolência e o reconhecimento original do amor, sempre articulam-se dentro de um étos ou vários étos já estabelecidos. Eles sempre são marcados por estes étos. Ao mesmo tempo, o amor originário tem a capacidade de subverter essas estruturas e de estabelecer um novo étos. Isso, porque o amor é a fonte originária de todos os étos, mesmo que estes tenham-se tornados avessos a própria amizade. É isso que Aristóteles afirma quando ele diz que toda comunidade é constituida na amizade e que onde há direito, há uma amizade também. ${ }^{11}$ Existe um constante processo dialético entre amor amigavel e étos comunal. Este processo muitas vezes é frutífero e harmonioso. Às vezes ele é conflituoso. Às vezes ele é violento. Às vezes ele é trágico.

A Filosofia da Amizade não tem mais a oferecer que isso. Ela apenas vai insistir que qualquer oferta que pretende poupar-nos dessa luta arduosa é uma ilusão e, ao longo prazo, não vai resolver o problema, mas vai agravá-lo.

O que segue disso para a questão do Estado? Primeiro, a partir do ponto de vista da Filosofia da Amizade, o estado volta a ser uma comunidade como as outras também. Não existe mais uma diferença essencial ou até ontológica do estado quanto aos demais tipos de comunidade. Se o estado é algo especial, se ele é o poder último na terra, ele é isso porque nós, ao longo da história, o formamos assim. E certamente tinha, sob o ponto de vista da amizade, razões muito boas para fazer isso. É muito profícuo para uma convivência amigável entre os cidadãos que o estado cuide de sua segurança interna e externa e que eles não precisam mais armar-se um contra o outro. É muito profícuo para o reconhecimento e a benevolência geral que exista um sistema jurídico neutro e independente que substitui o sistema da vingança particular. É 
muito proficuo para o desenvolvimento da liberdade e da igualdade na relação entre os membros do estado que este seja democrático e que cada membro seu, de alguma forma, possa participar no poder exercido nele. Acho que essas são conquistas históricas que não deveríamos abandonar e cujo enfraquecimento deveríamos combater fortemente. Pelo outro lado, o estado não é, necessariamente, a forma definitiva e absoluta da organização do poder político. Na realidade, ele já está no processo de perder este papel. A Filosofia da Amizade, outra vez, não oferece uma solução para o problema do enfraquecimento do estado em nosso tempo. Mas ela pelo menos possui flexibilidade suificente para enfrentar este desafio, porque não define um ponto de partida fixo: nem um indivíduo pronto, com sua identidade e seus interesses já definidos, que depois vai fechar o contrato social; nem uma comunidade pronta, seja ela real ou ideal, com seu étos e suas instituições já estabelecidas.

A Filosofia da Amizade não aposta em nada pronto, definitivo e acabado. Ela aposta no processo dialético, longo, espinhoso, que não tem um fim pré-definido, mas que exige que nos projetemos e corrigamos nossas finalidades sempre novamente. Ao mesmo tempo, ela não recai num relativismo ou niilismo absoluto, mas oferece critérios para este processo. O critério fundamental é o amor amigável, os critérios específicos são os momentos constitutivos deste que apresentei a partir de Aristóteles: o reconhecimento e a benevolência (junto com o desejo e o conhecer). Estes critérios podem até ser chamados aprióricos. Mas são critérios "aprióricosabertos", porque os conceitos de reconhecimento, benevolência etc. são apenas formas genêricas que exigem sua concretização nas condições históricas específicas que, por sua vez, não são predeterminadas por estes conceitos.

Com isso talvez acabe-se com a obsessão dos filósofos desde Platão até Marx e boa parte dos bons Democratas atuais que a salvação está na estrutura do Todo. "Só precisamos realizar a ordem certa no Estado, na sociedade, na economia, na cultura etc. - e todos os problemas acabarão.” Essa visão está errada, independentemente da questão se essa estrutura deve ser aquela do estado platônico, da monarquia de graças divinas, de um principado macchiavellista, de uma monarquia constuticonal, do socialismo, do comunismo, de uma república dos conselhos ou sindicatos, da democracia representativa, da democracia direta, do estado mundial federativo ou outra. Evidentemente, as estruturas e instituições da sociedade e do estado fazem parte da solução. Elas precisam fazer parte de qualquer proposta de solução aos grandes problemas que temos no ámbito político. Mas elas, por se só, nunca são $a$ solução. Se o século passado nos 
ensinou uma lição histórica, é essa. O último exemplo pode ser a segunda guerra iraquiana. “Apenas precisamos instalar a democracia neste país e tudo será logo resolvido”, era essa a ingênua expectativa de tantos Norte-Americanos. "Estúpidos", muitos vão dizer, tanto na Europa quanto aqui na América Latina - para, já na próxima sentença, voltar a explicar quais estruturas políticas realmente vão salvar o mundo. Este é o caminho errado. Isso não é apenas uma questão da experiência histórica. É, como tentei mostrar, uma questão lógica da construção sistemática do pensamento político.

\section{Conclusão}

Só pude começar a expor algumas das consequências da tentativa de compreender o estado a partir da realidade da amizade. Muito resta a explicar e esclarecer. E, como já indiquei, a Filosofia da Amizade implica muitos problemas, teóricos e práticos, que não resolvi aqui e que, talvez, não tenham solução. Portanto, minhas reflexões aqui apresentadas não podem ser mais que uma instigação, um convite a pensar o poder político de uma nova forma, de uma forma que pode ser vista até como paradoxal: compreender o político justamente a partir daquela realidade que, na opinião comum, é a mais privada: o amor amigável. 


\title{
Notas
}

\begin{abstract}
${ }^{1}$ Estes interesses podem ser puramente particulares ou já universalizados, como, p.ex., no caso de interesses morais (como, p.ex., em Kant). Mas mesmo neste último caso, continuam interesses do sujeito individual - e não interesses pertencentes a algo supra-individual.
\end{abstract}

${ }^{2}$ Este, evidentemente, é o velho argumento da auto-refutação do relativismo, repetido inúmeras vezes. Naturalmente, surgiram inúmeros contra-argumentos e estratégias para evitá-lo por parte dos relativistas e historicistas. Não tenho o espaço aqui para entrar nessa discussão, só posso notar que, a meu ver, não há como o relativismo - seja sua forma qual for - possa salvar-se deste argumento.

${ }^{3}$ Cf. A sociedade aberta e seus inimigos, Belo Horizonte: Itaiaia, ${ }^{3} 1998$. Foi argumentado muitas vezes que a argumentação de Popper, principalemente contra Platão e Hegel, é simplória. Concordo, mas acho que Popper identifica corretamente uma tendência subjacente nestes autores (e outros), mesmo que seja injusto chamar estes de totalitaristas (ou até fascistas, como, às vezes, acontece).

${ }^{4}$ Consequentemente, contra essa base não-contratualista de sua teoria do estado, podem ser direcionados os mesmos argumentos como contra o comunitarismo (naturalista ou idealista, dependento do carater dessa base).

${ }^{5}$ Com exeção do contratualismo hobbesiano, no qual o contrato constitui o Leviatã, o estado-sujeito ao qual todos os sujeitos individuais têm que submeter-se. Dentro da sistemática desenvolvida essa concepção poderia ser chamada de "comunitarismo contratual". Evidentemente este mostra a mesma marca da opção unilateral pela unidade e a identidade como as demais formas de contratualismo e comunitarismo.

${ }^{6}$ Cf. República, 367e ss.

${ }^{7}$ Cf. Ética a Nicômaco (EN), 1160a9 ss.

${ }^{8}$ Cf. K. UTZ, Die Notwendigkeit des Zufalls. Hegels spekulative Dialektik in der „Wissenschaft der Logik“, Paderborn: Schöningh, 2001.

${ }^{9} \mathrm{Na}$ verdade, Aristóteles fala explicitamente apenas da benevolência. Não posso entrar aqui na discussão por quê, a meu ver, o concepção do respeito também está inerente a seu conceito do amor amigável (cf. K. UTZ, Filosofia da Amizade: uma proposta.Ethic@(UFSC), v.7 (2008), 151-164).

${ }^{10}$ Para uma discussão muito diferenciada das vantagens e dos perigos da amizade no âmbito do político cf. J. DERRIDA, Politiques de l'amitié, Paris: Galilée, 1994; cf. tambem FRANCISCO ORTEGA, Para uma política da amizade: Arendt, Derrida, Foucault, Bonsucesso: Relume-Dumará, 2000.

${ }^{11}$ EN 1159b25s. 